\title{
Voluntary Counseling and Testing Utilization and Associated Factors among Arba Minch University Students, South Ethiopia
}

\author{
Selamawit Dagne ${ }^{1^{*}}$, Eskezyiaw Agedew ${ }^{2}$, Diresilign Misikir ${ }^{2}$ and Desta Haftu ${ }^{2}$
}

${ }^{1}$ Medanact Ethiopia, Southern Nation, Ethiopia

${ }^{2}$ Arba Minch University Public Health Department, Ethiopia

\begin{abstract}
Background: Voluntary Counseling and Testing (VCT) is the key entry point to prevention, care, treatment and support services, where people learn whether they are infected and are helped to understand the implications of their HIV status and make informed choices for the future.
\end{abstract}

Objective: The main objective of this study was to assess voluntary counseling and testing utilization and associated factors among Arba Minch University students.

Method: An Institution-based cross-sectional study design with quantitative data collection method was employed among 764 students drawn from selected departments of Arba Minch University; by using multi-stage sampling technique. Data was analyzed by using SPSS version 20.

Results: A total of 764 people responded the questionnaire out of 805 proposed study participants with the response rate of $94 \%$, of whom $77.6 \%$ were male. From the study participants $97.9 \%$ were knowledgeable about HIV transmission and prevention. The prevalence of HIV testing was $61.5 \%(95 \% \mathrm{Cl}=0.58,0.65)$. The findings also showed that the participants who are knowledgeable about HIV (AOR=4.46, 95\% $\mathrm{Cl}=2.00,9.89)$, who are willing to have VCT $(A O R=3.22,95 \% \mathrm{Cl}=1.98,5.25)$, who heard about presence of confidential testing (AOR=3.66, 95\% $\mathrm{Cl}=2.38,5.62)$ and who had sex $(\mathrm{AO}=1.71, \mathrm{Cl}=1.19,2.48)$ were more likely to be tested. Feeling at risk, fear of a positive result and fear of being stigmatized were reported as being the main barriers to VCT utilization.

Conclusion: Knowledge about HIV and VCT, willingness to have VCT and presence of confidential testing were independent factors identified as predictors for increased VCT service utilization.

Recommendation: More emphases should been given by concerned governmental and non-governmental organizations on independent factors identified as predictors for increased VCT service utilization and removing the main barriers to voluntary counseling and testing.

\section{Keywords: HIV; Sex; Counseling; Service; Treatment}

\section{Introduction}

Worldwide, only one in 10 HIV-positive individuals know their status, and the majorities in developing countries do not have access to HIV voluntary counseling and testing (VCT). It is estimated that 20$30 \%$ of HIV infected individuals in developed countries are unaware of their HIV status, while about $80 \%$ of people living with HIV in low and middle-income countries are unaware of their status [1]. This is particularly worrisome in sub-Sahara African countries, where just $12 \%$ of men and $10 \%$ of women have been tested for HIV and received their results $[2,3]$.

The HIV/AIDS epidemic is problematic among college students because of their vulnerability and the increasing incidence of HIV infection among the college student population. Students vulnerability has been attributed to their high levels of sexual activity, increasing incidence of risky sexual behaviors, and their inability to make accurate assessment of their own risk for HIV infection $[4,5]$.

University students are at risk because they tend to be sexually adventurous, often with multiple partners and do not consistently use condoms. Moreover youths, students of tertiary level, constitute a significant proportion of persons affected by HIV and all of them are also sexually active [6]. So increased utilization of HIV testing among university students has a paramount importance to reduce HIV related mortality and morbidity.

High-quality VCT enables and encourages people with HIV to access appropriate care and is an effective HIV-prevention strategy. VCT can also be an effective behavior-change intervention. VCT offers a holistic approach that can address HIV in the broader context of peoples' lives, including the context of poverty and its relationship to risk practice [7].

Voluntary Counseling and Testing enables people with HIV to seek emotional, social and medical care, and in areas of limited resources allows services to be channeled appropriately. It also enables people who test seronegative to access suitable support and services [8].

There are researches conducted indifferent universities in the Ethiopia on VCT utilization and associated factors [9-11], but there is no research conducted in the study area. In addition, since the study area is attractive and transit for many tourists, the youth, particularly, university students, are at risk of getting HIV, thus the aim of this study was to assess VCT service utilization and associated factors among Arba

*Corresponding author: Selamawit Dagne, Lecturer, Arba Minch University, Public Health 21, Arba Minch, Ethiopia, Tel: +251-920413878; E-mail: esk1agid@gmail.com Received January 19, 2017; Accepted June 21, 2017; Published June 28, 2017 Citation: Dagne S, Agedew E, Misikir D, Haftu D (2017) Voluntary Counseling and Testing Utilization and Associated Factors among Arba Minch University Students, South Ethiopia. J AIDS Clin Res 8: 704. doi: 10.4172/2155-6113.1000704

Copyright: (C) 2017 Dagne S, et al. This is an open-access article distributed unde the terms of the Creative Commons Attribution License, which permits unrestricted use, distribution, and reproduction in any medium, provided the original author and source are credited. 
Minch University students, South Ethiopia. The findings of the study will be helpful to expand and improve the service of VCT, contributing to the HIV/AIDS prevention and control programs in the Arba Minch University.

\section{Methods and Materials}

\section{Study area}

The study was conducted from December to January 2014, in Arba Minch University, which is located in Gamo Gofa Zone. It is located $505 \mathrm{~km}$ south of Addis Ababa. Two NGO, two government health centers and one hospital are providing VCT service. There is only one VCT center in the Arba Minch University. This university is far from the capital city Addis Abeba and students were join from diversified ethnic group and majority were rural and the rest come from regional city. Arba Minch University located in Semi urban areas near Zonal city with high tourist movement.

\section{Study design}

An Institution-based cross-sectional study design method was employed in this study to assess the magnitude of VCT utilization and associated factors among Arba Minch University students.

\section{Population}

Source population: All regular students in Arba Minch University.

Study population: All randomly selected regular university students and fulfilled the inclusion criteria.

\section{Inclusion and exclusion criteria}

The study population were all undergraduate regular students (Year I to year V) attending professional training at Arba Minch University. Extension students were excluded from the study.

\section{Sample size calculation}

The sample size for measuring VCT utilization is determined by Epi Info version 6 software package using single proportion formula for cross sectional survey, based on the prevalence of VCT service utilization (58.5\%) during the past year among Debre Markos University students [12]. Using 5\% margin of error at 95\% confidence level, design effect 2.

$$
\mathrm{N}=\underline{\mathrm{Z} \alpha / 2^{2}} \underline{\mathrm{p}(1-\mathrm{p})}
$$$$
\mathrm{d}^{2}
$$

The sample size required was 732 , after considering $10 \%$ nonresponse rate the total sample size was 805 .

\section{Sampling techniques}

Multistage sampling technique was used to select study participants. Firstly, the students in the university were stratified by their field of study as health science and none Health Science. Secondly, one department from Health Science and eight departments from non health science were selected randomly by using lottery method based on Arba Minch university registrar data. From the selected departments study participants were stratified based on year of study, and the sample size was allocated based on probability proportional to size allocation. Finally study participants from each batch were selected by simple random sampling method.

\section{Data collection procedures}

Data collection was done by pre-tested questionnaire with closed- ended questions. A structured questionnaire was adapted from Behavioral Sentinel Survey (BSS) $[2,13]$ and similar previous studies and sample of questionnaire was modified to the study setting. It was first developed in English then translated in to Amharic and again back to English to ensure its consistency by a language expert. Data collection was administered in Amharic. Pretesting of the questionnaire was conducted in one department of the university, which was not included in the study to verify clarity of the instrument. Based on the pre-test, questioners were revised, edited, and those found to be unclear or confusing were removed.

Two supervisors and four data collection facilitators were recruited. After being orientated about the study for one day and making them familiar with the questionnaire data was collected from each select department. Each questionnaire was checked for completeness of the information jointly by the supervisors.

\section{Data quality assurance}

Strict daily supervision by supervisors and investigator of the data collection process was maintained throughout the collection period. Supervisors were checked study sites and were received filled questionnaires from the data collectors daily and checked for completeness. Principal investigator was check study sites daily. Completed questionnaires were submitted to the principal investigator for final check. Among all filled questioners 15 were incomplete and discarded from analyses.

\section{Data entry and analysis}

The data obtained from study participants ware manually checked for completeness. The data was coded, cleaned and entered and analyzed using SPSS computer software package

Version16. Frequency distribution and cross tabulation were used for socio-demographic variables. Bivariate analysis was done and variables with a $\mathrm{P}$ value of less than 0.2 were included in the multiple logistic regression analysis, which was performed to assess the association between VCT utilization and various explanatory variables.

\section{Operational definition}

Knowledgeable about HIV/AIDS/VCT: Respondents scoring average and above, regarding mode of transmission, prevention, correct conception of HIV/AIDS and VCT [7,12].

Voluntary counseling and testing utilization: It is measured by requesting study participants getting HIV testing service voluntary in the last 12 months $[7,13]$.

\section{Ethical consideration}

Before the study was conducted ethical clearance was obtained from Ethical review Committee of Addis Continental Institute of Public Health. Permission to conduct the study in the university was secured from AMU. Informed consent from each study participants was obtained after explaining the purpose of the study. Privacy and strict confidentiality was maintained during the interview process. To ensure confidentiality of the information, any identification of study participants was recorded, and data collectors kept the information strictly confidential.

\section{Results}

\section{Socio demographic characteristics of respondents}

Interviews were done with 764 people responded the questionnaire 
out of 805 proposed study participants with the response rate of ninety four percent. Of whom $593(77.6 \%)$ were male. The mean age $( \pm$ SD) the respondents was $21( \pm 1.7)$. It is more about $99 \%$ of the participants were single. Two hundred sixty (34\%) of them have boy/girl friends. Among respondents $72.5 \%$ of them were come from urban area. More than half of the respondents were Orthodox believers 497 (65.1\%), followed by Protestant 164 (21.5\%) (Table 1).

\section{VCT utilization}

Among 764 students participated in the study, 470 (61.5\%) of them had VCT $(95 \%$ CI=58\%, 65\%). Of whom 364 (61.4\%) were male. Thirty four point four percent of the students in the age category 17-21 had VCT. Regarding year of study, $108(60 \%)$ of 1st year, $127(65.1 \%)$ of the $2^{\text {nd }}, 113(59.2 \%)$ of 3 rd year, $97(66.4 \%)$ of the $4^{\text {th }}$ year and $25(48.1 \%)$ of $5^{\text {th }}$ year students utilized VCT. About $69.7 \%$ of the students in health science department utilized VCT when we compare to $(60.6 \%)$ of the students utilized VCT in non health science department.

The major reason reported by respondents for utilizing VCT service was to know self, 409 (87\%) followed by requested by health worker, $80(15 \%)$. The study participants were asked about the reason for not utilizing VCT and about 157 (53.6\%) of the respondents reported not felt at risk, 65 (22.2\%) fear of positive result, 27(9\%) fear of stigma and $26(8.9 \%)$ reported partner and self-trust (Figure 1).

\section{Knowledge and attitude towards VCT among students}

Eighty five point five percent of the respondents have heard about VCT. Mass media was reported as primary source of information, followed by health workers. Ninety seven percent of the respondents who heard about VCT agreed that VCT is important. Eighty seven percent of the respondents were willing to take HIV test in the future weather they had it before or not. Regarding the preference of VCT service delivery institutions, $328(42 \%)$ of them choose government institutions to take HIV test, followed by private health institution 309 (39\%). Majority of the respondents reported good care and technical competence as a reason for preference of health institutions.

About $483(65.5 \%)$ of the respondents prefer health personnel

\begin{tabular}{|c|c|c|}
\hline Variable & Frequency & Percent \\
\hline Sex & & \\
Male & 593 & 77.6 \\
Female & 171 & 22.4 \\
\hline Age & & \\
$17-21$ & 445 & 58.2 \\
$22-26$ & 319 & 41.8 \\
\hline Marital states & 753 & \\
Single & 11 & 98.6 \\
Married & 3 & 1.4 \\
Divorced & & 0.4 \\
\hline Boy and girl friends & 260 & 34 \\
Yes & 504 & 66 \\
No & & \\
\hline (n) & 180 & 23.6 \\
\hline $1^{\text {st }}$ & 195 & 25.5 \\
$2^{\text {nd }}$ & 191 & 19.1 \\
3rd & 146 & 6.8 \\
\hline $4^{\text {th }}$ & 52 & 72.5 \\
$5^{\text {th }}$ & & 27.5 \\
\hline Previous residence & 554 & \\
Urban & 210 & \\
\hline Rural & & \\
\hline
\end{tabular}

Table 1: Socio-demographic characteristics of the respondents in Arba Minch University, 2014. to provide HIV counseling and 160 (17\%) prefer peer counselors. Regarding convenient time for VCT service delivery, 410 (55.3\%) preferred at weekends followed by, $92(25.9 \%)$ in the usual working hours. Majority of the respondents, $523(70.8 \%)$ prefer face to face to obtain VCT results. About 646 (87.1\%) of the respondents reported the preferable time to get the results was the same day.

\section{Sexual characteristic and risk perception of study participants}

Among 764 respondents, 273 (35.7\%) ever had sex in past 12 months. The reported age of sexual debut ranged between 12 to 23 years with mean age $( \pm$ SD) $18 \pm 1.7$. The minimum age at first sexual intercourse for males and females were 12 and 16 years, respectively. Among two hundred seventy three sexually active respondents, 101 (39.9\%) had sexual intercourse with more than one partners. Regarding condom practice, 144 (56.7\%) of who gave history of sexual contact in the past one year had ever used condom.

Level of risk perception of students for HIV infection was examined in order to see their insight against their actual risk behaviors for HIV infection. Only seventeen point seven percent of respondents perceived that they are at the risk of acquiring HIV.

\section{Factors associated with VCT utilization}

In order to identify factors that are associated with VCT utilization, a two stage regression analysis - binary and multiple logistic regressions were used. In order to control the effect of confounders a multiple logistic regression was done. The factors included in the model were those that showed significant association at the binary logistic regression analysis at a cut of value ( $p$ value $\leq 0.2$ ) Knowledge about HIV and VCT, presence of confidential testing, willingness to have VCT, perceived importance of VCT, perceived risk of HIV, being sexually active and socio demographic factors. The findings indicated that, socio-demographic characteristics of the students were not associated with VCT service utilization. Students who were knowledgeable about HIV transmission and prevention were four times more likely to utilize VCT than those who were not knowledgeable ( $\mathrm{AOR}=4.46,95 \% \mathrm{CI}=2.00$, 9.89), students who have willingness to have VCT were about three times more likely to be tested when compared to who were not willing ( $\mathrm{AOR}=3.22,95 \%$ $\mathrm{CI}=1.98,5.25)$. The respondents who heard about confidential HIV testing were four times more likely to be tested than their counterparts (AOR=3.66, 95\% CI=2.00, 9.89). The students who ever had sexual intercourse were two times more likely to be tested than those who had not had sexual intercourse $(\mathrm{AO}=1.71, \mathrm{CI}=1.19,2.48)$ (Table 2).

\section{Discussion}

This study revealed that VCT utilization among university students was $61.5 \%$. This study is in line with the study conducted in North West Ethiopia (61.8) and the study conducted in Debre Markos University $(58.5 \%)$ of the respondents having had VCT respectively $[14,15]$. On the contrary, a study conducted among private university students in Ghana revealed that $47.5 \%$ of the respondents have had VCT and among Addis Ababa university students $47.2 \%$ had been tested for HIV $[16,17]$. The possible explanation for this high VCT utilization could be the current study included both health and none health science students but the study conducted in Ghana and Addis Ababa may not be included health science students since the health science student had better understanding on VCT as compared to others student this improve their utilization. In addition this might be due to improved VCT service currently in terms of accessibility and awareness creation 


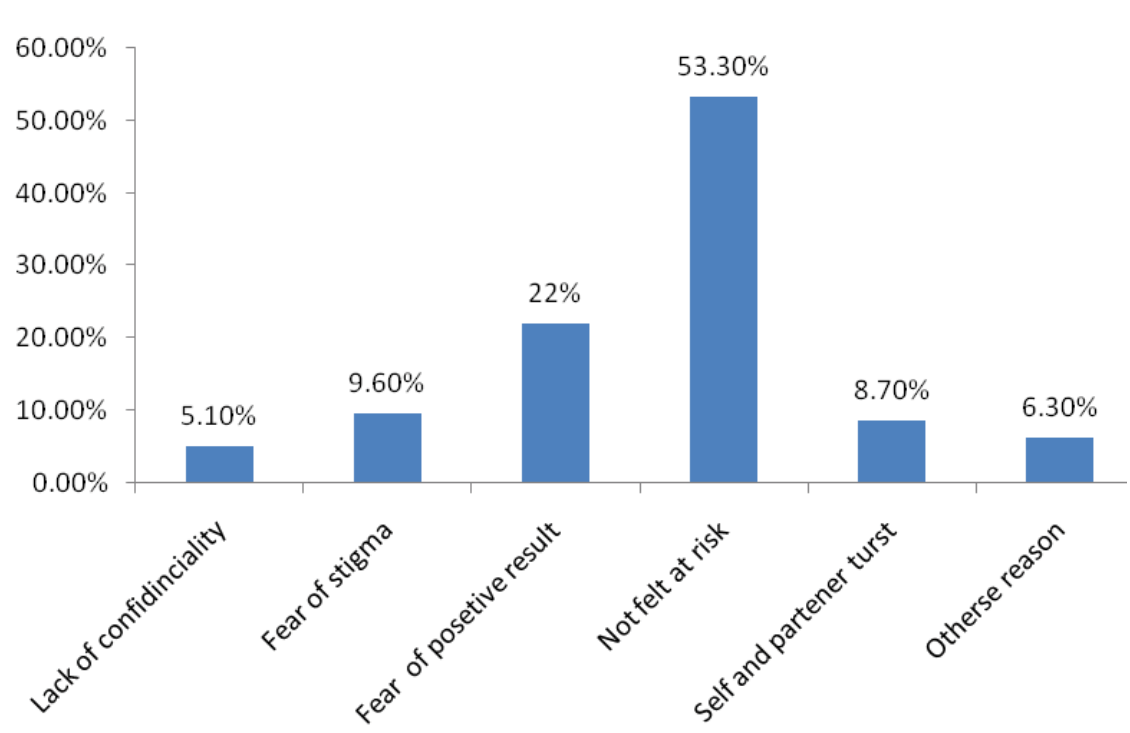

Figure 1: Reason of respondents not utilizing VCT service, Minch university students, South Ethiopia 2014.

\begin{tabular}{|c|c|c|c|c|}
\hline Variables & \multicolumn{2}{|c|}{$\begin{array}{c}\text { VCT Utilization } \\
\text { Yes }(n=479) \text { No( } n=294)\end{array}$} & \multirow{2}{*}{$\begin{array}{c}\text { COR }(95 \% \text { C.I) } \\
\begin{array}{c}6.53(3.18,13.38) \\
1\end{array}\end{array}$} & \multirow{2}{*}{$\begin{array}{c}\text { AOR (95\% C.I) } \\
\begin{array}{c}4.46(2.00,9.89) \\
1\end{array}\end{array}$} \\
\hline $\begin{array}{l}\text { Knowledge on HIV } \\
\text { Knowledgeable HIV } \\
\text { Not Knowledgeable }\end{array}$ & $\begin{array}{c}460(64.2 \%) \\
10(20.8 \%)\end{array}$ & $\begin{array}{c}256(35.8 \%) \\
38(79.2 \%)\end{array}$ & & \\
\hline $\begin{array}{c}\text { VCT Knowledge } \\
\text { Yes } \\
\text { No }\end{array}$ & $\begin{array}{c}465(66.8 \%) \\
5(7.4 \%)\end{array}$ & $\begin{array}{c}231(33.2 \%) \\
63(92.6 \%)\end{array}$ & $\begin{array}{c}19.56(8.8,48.5) \\
1\end{array}$ & $\begin{array}{c}9.93(3.69,21.69) \\
1\end{array}$ \\
\hline $\begin{array}{c}\text { Willingness to have VCT } \\
\text { Yes } \\
\text { No }\end{array}$ & $\begin{array}{c}435(65.4 \%) \\
35(35.4 \%)\end{array}$ & $\begin{array}{c}230(34.6 \%) \\
64(64.6 \%)\end{array}$ & $\begin{array}{c}4.12(2.62,6.47) \\
1\end{array}$ & $\begin{array}{c}3.22(1.98,5.25) \\
1\end{array}$ \\
\hline $\begin{array}{c}\text { Confidential testing } \\
\text { Yes } \\
\text { No }\end{array}$ & $\begin{array}{c}422(71.3 \%) \\
48(27.9 \%)\end{array}$ & $\begin{array}{l}170(28.7 \%) \\
124(72.1 \%)\end{array}$ & $\begin{array}{c}6.81(4.64,9.99) \\
1\end{array}$ & $\begin{array}{c}3.66(2.38,5.62) \\
1\end{array}$ \\
\hline $\begin{array}{c}\text { Ever had sex } \\
\text { Yes } \\
\text { No }\end{array}$ & $\begin{array}{l}188(69.4 \%) \\
282(57.2 \%)\end{array}$ & $\begin{array}{c}83(30.6 \%) \\
211(42.8 \%)\end{array}$ & $\begin{array}{c}1.73(1.26,2.38) \\
1\end{array}$ & $\begin{array}{c}1.71(1.19,2.48) \\
1\end{array}$ \\
\hline
\end{tabular}

Table 2: Association of VCT utilization with selected variables among Arba Minch University students, 2014.

and also VCT campaign in the study area. However, this study result was low when we compare with study conducted in Kenya; among Mount Kenya University students $76 \%$ of them have had VCT [18]. This may be due to the fact that the risk perception among Mount Kenya university students was high when compared to the current study.

The finding of this study indicated that the knowledge about HIV/ AIDS transmission and prevention was $94 \%$. Knowledge about HIV and VCT has shown significant association with VCT utilization. Students who were knowledgeable about HIV transmission and prevention were five times more likely to utilize VCT than those who were not knowledgeable. This is attributed to the fact that VCT users could have more knowledge regarding HIV/AIDS and VCT before they came to VCT centers.

In this study willingness to have VCT reported to be a possible predictor of VCT utilization. Students who had a desire to have VCT in the future were four times more likely to have VCT when we compared them with their counterparts. This could be attributed to the fact that positive attitude has a great roll in VCT utilization. Making every attempt to bring attitude change among students would help to increase VCT utilization.

The other finding of current study, there was significance association between VCT utilization and presence of confidential testing. The study participants who heard about presence of confidential testing were four times more likely to be tested than that of their counterparts. This finding is also similar with the study conducted among Debre Markos University students [15] the possible reason for this could be due to the fact that HIV remains a stigmatizing condition, people feel more comfortable to take VCT service when they are sure about the issue is kept in secret.

A plan to know their HIV status was the most common reason reported by the study participant for utilizing VCT. It comprises $86.6 \%$. This finding is similar with study conducted among Debre Markos university students, collages of Harer, comprises $82 \%$ and $89 \%$, respectively $[15,10]$. Not felling at risk, fear of positive result, fear of 
stigma \& self and partner trust were reported reasons for not utilizing VCT, which constitute $53.6 \%, 22.2 \%, 9.5 \%$ and $8.9 \%$, respectively. This is in agreement with the study conducted in North West Ethiopia and among health professional students Tanzania $[6,14]$.

The study identified sexually active students were two times more likely to be tested than those who never had sex before. This result is in line with a studies conducted in collages of Harer [19]. The reason could be sexually active students triggered to know their HIV status due to perceived risk of getting HIV, while those who never had sex were unwilling to know their status by considering themselves as low risk.

In this study a significant proportion of students perceived themselves as being low risk for acquiring HIV/AIDS, despite of the fact that, thirty five point seven participants were sexually active with higher proportion of students of age group 17-21, forty percent of sexually active participants have had multiple sexual partners, while 43.3\% of them had had unprotected sex. Similarly, studies conducted among High school students in Cameron and Perception of Ethiopian youth regarding their risk of HIV were revealed that risk perception of HIV among the youth was $18 \%$ and $19 \%$, respectively $[13,20]$.

The study tried to explore whether the socio demographic characteristics influences the VCT up take of the students. The findings revealed that sixty nine point seven percent of the students in health science department were utilized VCT. This might be due to the fact that by being the health science students they have better knowledge, attitude and access towards VCT than their counterparts. But there was no association between the socio demographic characteristics and VCT utilization. This corresponds with studies conducted in Debremarkos and Mekele University [12,15]. This study is inconsistent with KAP among University students North West Ethiopia and unmatched case control study conducted in Bahirdar University, which revealed that there was significant association between VCT utilization and socio demographic characteristics $[6,19]$. The possible reason could be due to a strong and collaborative effort of government and Non government organizations expanding the service through awareness creation and mass mobilization throughout the country without making any difference in age, sex, marital status and residence.

\section{Limitation of the Study}

- Cross-sectional nature of study, difficult to show causal association and trends in VCT utilization.

- The current study may not be generalized to the whole young people because the study involved only those young people who are in higher institutions

\section{Conclusion and Recommendation}

This study reveled that VCT utilization is moderate. There it possible to improve the utilization by working on modifiable factors like improving privacy of test and their VCT Knowledge. More emphases should have been given by concerned governmental and nongovernmental organizations on independent factors identified as predictor for increased VCT service Utilization and main barriers. Health education about HIV needs to be provided with more emphases on helping the students to internalize the risk of acquiring HIV in order to enhance VCT utilization. Further research is needed by using different study design which shows cause and effect relationship.

\section{Acknowledgement}

We would like to thank Arba Minch University and Addis Continental institute of Public Health for giving this chance. We also like to thank our colleagues for their valuable comment and support. Next we are greatly indebted to Arba Minch University instructors. We extend our gratitude to our data collectors and participant for their unreserved participation in our study.

\section{Authors' Contribution}

SD: Initiated the research, wrote the research proposal, conducted the research, did data entry and analysis and wrote the manuscript. EA: Involved in the write up of methodology of proposal and research work. DH and DM: Contributed in the designing of methodology, write up of proposal, did the analysis and write up of the manuscript.

\section{References}

1. Joint United Nations Program on AIDS (2010) Getting to zero: 2011-2015 strategy. UNAIDS, Geneva.

2. Central Statistical Agency, ICF International (2011) Ethiopia demographic and health survey 2011. Central Statistical Agency, Addis Ababa, Ethiopia, ICF International, Calverton, Maryland, USA.

3. Bateganya M, Abdulwadud OA, Kiene SM (2010) Home-based HIV voluntary counseling and testing (VCT) for improving uptake of HIV testing. Cochrane Database Syst Rev 7: CD006493.

4. Ayodele $O$ (2007) The socio demographic and psychosocial determinants of HIV voluntary counseling and testing among Nigerian university student. Proquest.

5. Boswell D, Baggaley R (2002) Voluntary counseling and testing (VCT) and young people: A summary overview. Family Health International.

6. Lawrence Meda (2013) Assessing factors influencing university student's uptake voluntary counseling and testing (VCT) of human immune deficiency virus/ acquired immune deficiency syndrome (HIVIAIDS). J AIDS HIV Res 5: 173-180.

7. Addis Z, Yalew A, Shiferaw Y, Alemu A, Birhan W, et al. (2013) Knowledge attitude and practice towards voluntary counseling and testing among university students in North West Ethiopia. BMC Public Health 13: 714

8. WHO (2010) Scaling up priority HIVIAIDS interventions in the health sector, progress. World Health Organization, United State.

9. Country Progress Report on HIVIAIDS Response, 2012 (2012) Federal Democratic Republic of Ethiopia.

10. UNAIDS (2001) The impact of voluntary counseling and testing: A global review of the benefits and challenge Joint United Nations Program on HIVIAIDS.

11. Tsegay G, Edris M, Meseret S (2013) Assessment of voluntary counseling and testing service utilization and associated factors among Debre Markos University Students, North West Ethiopia: A cross-sectional survey. BMC Public Health 13: 243.

12. Asante KO (2013) HIVIAIDS knowledge and uptake of HIV counseling and testing among undergraduate private university students in Accra, Ghana. Reproductive Health 10: 17.

13. Mitike M, Yemane B, Bernt L (2009) Perception of Ethiopian youth regarding their risk of HIV: A community-based study among youth in predominately rural Butajira. Ethiop J Rep Health 3: 44-51.

14. Dirar A, Mengiste B, Kedir H, Godana W (2013) Factors contributing to voluntary counseling and testing uptake among youth in colleges of Harare Ethiopia. Sci J Public Health 1: 91-96.

15. Regassa N, Kedir S (2011) Attitudes and practices on HIV preventions among students of higher education institutions in Ethiopia: The case of Addis Ababa University. East Afr J Public Health 2: 828-840.

16. Museve J, George GE, Labongo CL (2014) An analysis of uptake in HIV voluntary counseling and testing services: Case of Mount Kenya University Students, Kenya. Public Policy and Administration Research 3.

17. Tewabe T, Destaw B, Admassu M, Abera B (2012) Assessment of factors associated with voluntary counseling and testing uptake among students in Bahir Dar University: A case control study Ethiop. J Health Dev 26: 16-21.

18. Charles MP, Kweka EJ, Mahande AM (2009) Evaluation of uptake and attitude to voluntary counseling and testing among health care professional students in Kilimanjaro region, Tanzania. BMC Public Health 9: 128. 
Citation: Dagne S, Agedew E, Misikir D, Haftu D (2017) Voluntary Counseling and Testing Utilization and Associated Factors among Arba Minch University Students, South Ethiopia. J AIDS Clin Res 8: 704. doi: 10.4172/2155-6113.1000704

Page 6 of 6

19. Bayray A (2010) Knowledge, attitude and practice of voluntary counseling and testing for HIV among university students, Tigray, Northern Ethiopia. MEJS 2: 108-118.
20. Haddison EC, Nguefack-Tsagué G, Noubom M, Mbatcham W, Martins P, et al. (2012) Voluntary counseling and testing for HIV among high school students in the Tiko health district, Cameroon. Pan Afr Med J 13: 18 